\title{
$A P C$ gene is modulated by hsa-miR-135b-5p in both diffuse and intestinal gastric cancer subtypes
}

Leandro Magalhães ${ }^{1}$, Luciana Gonçalves Quintana ${ }^{2}$, Dielly Catrina Favacho Lopes ${ }^{3}$, Amanda Ferreira Vidal ${ }^{1}$, Adenilson Leão Pereira', Lara Carolina D’Araujo Pinto ${ }^{4}$, João de Jesus Viana Pinheiro ${ }^{4}$, André Salim Khayat ${ }^{2,6}$, Luiz Ricardo Goulart ${ }^{5}$, Rommel Burbano ${ }^{2,6}$, Paulo Pimentel de Assumpção ${ }^{2}$ and Ândrea Ribeiro-dos-Santos ${ }^{1,2^{*}}$ (D)

\begin{abstract}
Background: Several genetic and epigenetic alterations are related to the development and progression of Gastric Cancer (GC), one of those being the deregulated microRNA (miRNA) expression profile. miRNAs are small noncoding RNAs that negatively regulate the expression of thousands of genes, including oncogenes and tumor suppressor genes. Our group identified, in previous studies, some miRNAs that are differentially expressed in GC when compared to the gastric mucosa without cancer, including hsa-miR-29c and hsa-miR-135b. The aim of the study was to modulate the expression of the miRNAs $h s a-m i R-29 c-5 p$ and $h s a-m i R-135 b-5 p$ and evaluate the expression of their target genes in 2D and 3D cell cultures.

Methods: $h s a-m i R-29 c-5 p$ and hsa-miR-135b-5p expression profiles were modulated by transfecting mimics and antimiRs, respectively, in 2D and 3D cell cultures. The expression of the proteins coded by the genes CDC42, DNMT3A (target genes of hsa-miR-29c-5p) and APC (target gene of hsa-miR-135b-5p) were measured by Western Blot.

Results: Results showed that mimics and antimiRs transfection significantly altered the expression of both miRNAs, increasing the expression of $h s a-m i R-29 c-5 p$ and reducing the expression of $h s a-m i R-135 b-5 p$, especially in the 3D culture of the cell lines. When analyzing the proteins expression, we observed that AGP01 and AGP03 cell lines transfected with mimics had a reduction in the levels of CDC42 and DNMT3A and all three cell lines transfected with antimiRs had an increase in the expression of the protein APC.

Conclusion: We concluded that three-dimensional culture can be a more representative in vitro model that resembles better the in vivo reality. Our results also showed that $h s a-m i R-29 c-5 p$ is an important regulator of CDC42 and DNMT3A genes in the intestinal subtype gastric cancer and hsa-miR-135b-5p regulates the APC gene in both intestinal and diffuse subtypes of GC. Dysregulation in their expression, and consequently in their respectively signaling pathways, shows how these miRNAs can influence the carcinogenesis of different histological subtypes of gastric cancer.
\end{abstract}

Keywords: Gastric cancer, Hsa-miR-29c-5p, Hsa-miR-135b-5p, 3D culture, DNMT3A, CDC42, APC

\footnotetext{
* Correspondence: akelyufpa@gmail.com

${ }^{1}$ Laboratório de Genética Humana e Médica, Instituto de Ciências Biológicas,

Universidade Federal do Pará, Belém, Brazil

${ }^{2}$ Núcleo de Pesquisas em Oncologia, Hospital Universitário João de Barros

Barreto, Universidade Federal do Pará, Belém, Brazil

Full list of author information is available at the end of the article
}

(c) The Author(s). 2018 Open Access This article is distributed under the terms of the Creative Commons Attribution 4.0 International License (http://creativecommons.org/licenses/by/4.0/), which permits unrestricted use, distribution, and reproduction in any medium, provided you give appropriate credit to the original author(s) and the source, provide a link to the Creative Commons license, and indicate if changes were made. The Creative Commons Public Domain Dedication waiver (http://creativecommons.org/publicdomain/zero/1.0/) applies to the data made available in this article, unless otherwise stated. 


\section{Background}

Gastric Cancer (GC) is the fifth most common type of cancer and the third leading cause of death by cancer worldwide, representing an important issue in public health. Despite the decline in the worldwide GC incidence and mortality rates, South America remains the third leading world area in incidence of this cancer $[1,2]$.

GC is a multifactorial and complex disease in which genetic, epigenetic and environmental alterations contribute to its development and progression [3]. Significant advances in the understanding of the molecular aspects of such complex disease was made possible due in vitro experimentation in GC cell cultures. The most common cell culture model is growing the cells in monolayer or two-dimensional (2D) culture, however that method does not represent fully the cell-cell signaling or microenvironment features of an in vivo tumor, creating a need of establishing three-dimensional (3D) cultures to minimize the differences between cell culture and the living tissue of a cancer $[4,5]$.

One of the many molecular mechanisms altered in GC is the differential expression of microRNAs (miRNAs), small noncoding regulatory RNAs $(\sim 23 \mathrm{nt})$ that plays important role in the post-transcriptional regulation of gene expression by inhibiting the translation of its target messenger RNA (mRNA) through binding on its 3' UTR region [6-8].

miRNAs can regulate hundreds of target mRNAs, thus creating a extended and complex regulatory network of several signaling pathways, including those of oncogenes and tumor suppressor genes such as WNT and PI3K pathways [9-12]. Altered expression of these miRNAs in the tumor consequently modifies the function of its target genes, some of which regulate important cellular mechanisms for the cancer such as growth, proliferation, invasion and metastasis [13-15].

In previous works from our group, we identified through next generation sequencing miRNAs that composed a molecular signature of the gastric antrum and were differentially expressed between GC and the normal tissue, such as hsa-miR-204, hsa-miR-150, hsa-miR-29c and hsa-miR-135b $[7,16]$. Among the miRNAs differentially expressed, $h s a-m i R-29 c-5 p$ and $h s a-m i R-135 b-5 p$ were selected to be further investigated, because they were among the most differentially expressed miRNAs and also showed to be progressively dysregulated in the gastric precancerous cascade (Correa's Cascate) [17].

Both $h s a-m i R-29 c-5 p$ and $h s a-m i R-135 b-5 p$ play important roles not only in GC but in several types of cancer and are found to be down- and up-regulated, respectively, in gastric adenocarcinoma. $H s a-m i R-29 c-5 p$ regulates genes such as DNMT3A, CDC42, RCC2 and CDK6 and hsa-miR-135b-5p regulates genes such as APC, MID1 and MTCH2 [9, 18-20]. The consequent abnormal expression of the genes regulated by these miRNAs leads to carcinogenesis process, influencing at tumor progression and cellular growth.

Since little is known about the expression of both $h s a$ $m i R-29 c-5 p$ and $h s a-m i R-135 b-5 p$ in a three-dimensional condition and the $3 \mathrm{D}$ culture seems to resemble better the in vivo conditions of a tumor, there is a need to investigate the role of these miRNAs in such environment to further validate them as biomarkers and our study is the first one to consider the expression of both miRNAs in the 3D environment of gastric cancer cells. In this study, we induced the ectopic expression of $h s a-m i R-29 c-5 p$ and inhibited the action of $h s a-m i R-135 b-5 p$ in three GC cell lines, both in monolayer and three-dimensional models and, additionally, evaluated the expression of their target genes $D N M T 3 A, C D C 42$ and $A P C$.

\section{Methods}

\section{Gastric cancer cell lines and miRNA mimics and antimiRs} transfection

AGP01, ACP02 and ACP03 cell lines, previously established by our group [21], were cultured in DMEM containing $10 \%$ fetal bovine serum at $37{ }^{\circ} \mathrm{C}$ in $5 \% \mathrm{CO}_{2}$. AGP01 is a cell line established from gastric cancer cells present in the ascitic fluid of a patient with intestinal gastric adenocarcinoma, ACP03 is a cell line derived from a primary intestinal subtype gastric adenocarcinomas and ACP02 is a cell line derived from a primary diffuse subtype gastric adenocarcinoma. All culturing conditions were the same for all three cell lines.

All cell lines were also converted from 2D to 3D by magnetic levitation utilizing Bio-Assembler Kit (n3D Biosciences) according to the manufacturer's instruction. Briefly, $200 \mu \mathrm{L}$ of magnetic nanoparticles were added in the medium of a $25 \mathrm{~cm}^{2}$ flask with at least $80 \%$ confluence and then incubated overnight. In the next day, cells were trypsinized, $2 \times 10^{5}$ cells were seeded in each well of a 24-well plate and a magnetic drive was placed on top of the plate to make the cells levitate.

Cells, both in 2D and 3D, were transfected with $100 \mathrm{nM}$ of the following: mirVana ${ }^{\mathrm{\tau м}} h s a-m i R-29 c-5 p$ mimics (MC11335), hsa-miR-135b-5p miRNA Inhibitor (MH13044) and Negative Control (4464058) (Thermo Fisher, Waltham, MA, USA) according to the manufacturer's instructions. Transfection in 3D cultures were performed after at least $72 \mathrm{~h}$ of magnetic levitation. All transfections were performed in triplicates.

\section{RNA isolation and quantitative reverse-transcription real time PCR}

Total RNA was extracted from the cell lines using the High Pure miRNA Isolation Kit (Roche LifeSciences, Penzberg, Germany) according the manufacturer's instructions. RNA was quantified using a Qubit 2.0 fluorometer (ThermoFisher 
Scientific, Waltham, MA, USA) and was then stored at $-80{ }^{\circ} \mathrm{C}$ until performing miRNA profiling.

cDNA was synthetized from 10 ng of total RNA using the TaqMan MicroRNA Reverse Transcription kit (ThermoFisher Scientific) following the manufacturer's instructions. qRT-PCR was performed in a ABI Prism 7500 thermal cycler using TaqMan Universal Master Mix II and TaqMan MicroRNA Assays for hsa-miR-29c-5p (001818), hsa-miR-135b-5p (002261) and Z30 (001092) according to the manufacturer's instructions. All Realtime PCR reactions were performed in triplicate and the average of the results was used in subsequent analysis.

To evaluate differences in the expression levels between each group, the comparative Ct method was used [22], and the endogenous control Z30 was utilized to normalize the expression values.

\section{In silico prediction of hsa-miR-29c-5p and hsa-miR-135b- $5 p$ target genes}

To identify possible target genes that are regulated by the two miRNAs, we used two online databases: TargetCompare (lghm.ufpa.br/targetcompare) and miRTarBase (mirtarbase.mbc.nctu.tw). TargetCompare is a database that allows the user to filter miRNAs and its targets that are associated with determined diseases, and we filtered the results that were associated with GC. MiRTarBase is a database that predicts targets that have already been validated by molecular biology techniques.

We only considered relevant to the study the genes predicted by both plataforms that had relation with cancer and had a strong evidence of validation (Luciferase Reporter assays, Western Blot or qPCR) indicated by miRTarBase.

\section{Western blotting}

Western blot analysis was carried as described by Munhoz et al. [23]. Briefly, cells were scrapped and homogenized in cold PBS (supplemented with $1 \mathrm{mM}$ PMSF [phenylmethylsulfonyl fluoride]) and centrifuged at $4{ }^{\circ} \mathrm{C}$ for $5 \mathrm{~min}$ at 13,000 $\mathrm{g}$. The pellets were suspended in RIPA buffer (Sigma Aldrich, St. Louis, MO, USA) according to manufacturer's instructions. Samples were incubated on ice under agitation for $15 \mathrm{~min}$, and centrifuged for $5 \mathrm{~min}$ at $10,000 \mathrm{~g}$ at $4{ }^{\circ} \mathrm{C}$. Supernatants were used as total protein and stored at $-80{ }^{\circ} \mathrm{C}$. Protein concentration was determined using the Bio-Rad protein reagent.

Proteins were denatured in Laemmli sample buffer including 5\% $\beta$-mercaptoethanol (Bio-Rad Laboratories Inc., Hercules, CA, USA) for $5 \mathrm{~min}$ at $95{ }^{\circ} \mathrm{C}$. Electrophoresis was performed using $7.5 \%$ polyacrylamide gel and Bio-Rad Mini-Protean Tetra Apparatus, transferred to a PVDF membrane (Millipore, Billerica, MA, USA). Membrane was blocked for at least $45 \mathrm{~min}$ in $10 \%$ Tween 20 diluted in Tris-buffered saline (TBS-T) and
5\% fat-free milk. After that, the membrane was incubated with rabbit anti-DNMT3A antibody (1:2000; Abcam, Cambridge, UK), rabbit anti-CDC42 antibody (1:10000, Abcam), and rabbit anti-APC antibody (1:1000, Abcam), all of them overnight at $4{ }^{\circ} \mathrm{C}$. Proteins recognized by antibodies were revealed by a chemiluminescent reagent (Pierce $^{\text {tw }}$ ECL Western Blotting Substrate, Thermo Scientific) following the manufacturer's instructions. $\beta$-Actin (1:200, Abcam) was used as an internal control of the experiments.

\section{Statistical analysis}

Shapiro-Wilk test was utilized to verify the normality of the distribution of the miRNA expression data. Comparisons between the groups were made utilizing Student's $\mathrm{T}$ test (for parametric analysis).

$P$ values $<0.05$ were considered statistically significant, all tests and graphics were made using the $R$ statistical package (ver. 3.3.1).

\section{Results}

hsa-miR-29c-5p and hsa-miR-135b-5p expressions did not differ between 2D and 3D cultures of the ACP03 cell line

We evaluated the $h s a-m i R-29 c-5 p$ and $h s a-m i R-135 b-5 p$ expressions in both 2D and 3D models of the cell lines AGP01, ACP02 and ACP03 and observed that all expression profiles followed a Gaussian distribution, so parametric tests were applied to verify differences between groups.

When we compared the hsa-miR-29c-5p expression between $2 \mathrm{D}$ and $3 \mathrm{D}$ cultures, we observed that the expression of this miRNA was lower in the 3D model of ACP02 cell line $(P=0.04$, Fig. 1a), with a fold change of - 4.3. The expression of this miRNA was not statistically different between the two culture models of AGP01 and ACP03 cell lines $(P=0.12$ and $P=0.49$, respectively).

As for the hsa-miR-135b-5p expression, we observed that the 3D model of the AGP01 had significantly higher levels of this miRNA in comparison to the 2D culture $(P=$ 0.0067, Fig. 1b), representing a fold change of 29. ACP02 and ACP03 cell lines showed no significant difference of hsa-miR-135b-5p expression between culture models $(P=$ 0.14 and $P=0.22$, respectively). A statistical summary of the results is presented in Additional file 1: Table S1.

\section{hsa-miR-29c-5p mimics and hsa-miR-135b-5p antimiRs transfection significantly altered the miRNAs expression profiles in AGP01, ACP02 and ACP03 cell lines}

Both miRNAs expressions were measured after $24 \mathrm{~h}$ after the transfection of mimics and antimiRs (Fig. 2). We observed that there was a significant increase in $h s a-m i R-29 c-5 p$ expression and a significant reduce in hsa-miR-135b-5p expression in all three cell lines, both in $2 \mathrm{D}$ and in $3 \mathrm{D}$ models, when compared to the negative control cells. 

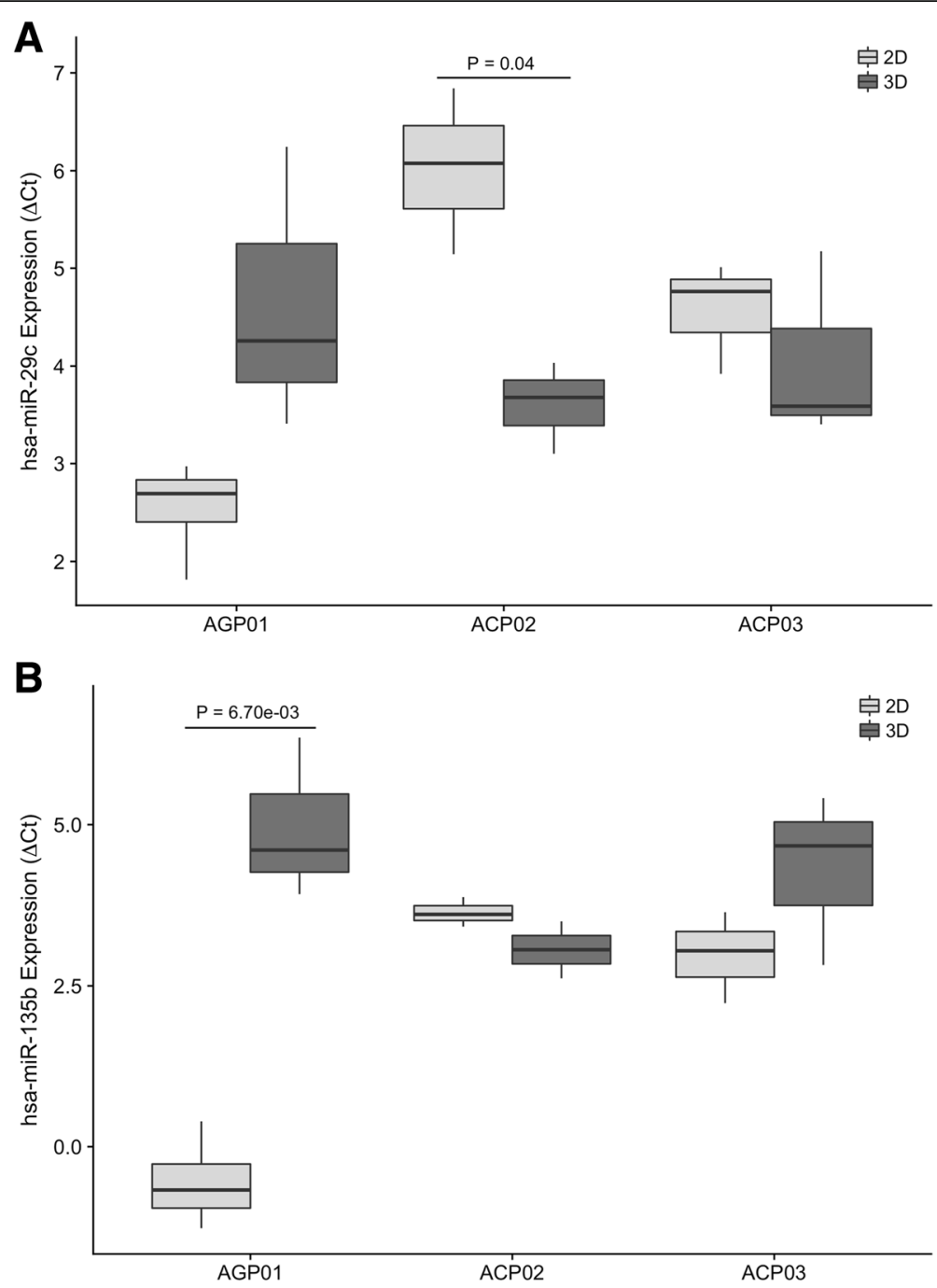

Fig. 1 hsa-miR-29c-5p (a) and hsa-miR-135b-5p (b) expression profiles in 2D and 3D cultures of AGP01, ACP02 and ACP03 cell lines. (a) hsa-miR$29 c-5 p$ was significantly down-regulated in the 3D culture of ACP02 cell line $(P=0.04)$ and did not differ significantly in the other two cell lines. $\mathbf{b}$ hsa-miR-135b-5p was significantly up-regulated in the 3D culture of AGP01 cell line $(P=0.0067)$ and was not differentially expressed in the other two cell lines. Student's T test was used to determine statistical significance

In AGP01 cell line, cells that were transfected with hsa-miR-29c-5p mimics had a 24-fold increase of this miRNA in the $2 \mathrm{D}$ model $(P=0.006$, Fig. $2 \mathrm{a})$ and a 23-fold increase in the 3D model $(P=0.02$, Fig. 2b). Cells transfected with hsa-miR-135b-5p antimiRs had a -2.3 -fold reduction of the mentioned miRNA in the 2D model $(P=0.03$, Fig. $2 \mathrm{c})$ and a -38 -fold reduction in the 3D model $(P=0.02$, Fig. $2 \mathrm{~d})$.

In ACP02 cell line, the transfection of mimics increased in 70-fold the $h s a-m i R-29 c-5 p$ expression in the 2D model $(P=0.0009$, Fig. $2 \mathrm{a})$ and 130 -fold in the 3D model $(P=0.0006$, Fig. 2b). Cells transfected with $h s a-m i R-135 b-5 p$ antimiRs had its expression reduced in -30 -fold in the 2D model $(P=0.015$, Fig. $2 \mathrm{c})$ and in -15 -fold in the $3 \mathrm{D}$ culture $(P=0.0007$, Fig. $2 \mathrm{~d})$.
Lastly, ACP03 cells that were transfected with mimics had an increase of 87 -fold of $h s a-m i R-29 c-5 p$ expression in the $2 \mathrm{D}$ model $(P=0.0002$, Fig. $2 \mathrm{a})$ and a 117 -fold increased expression in the 3D model $(P=0.002$, Fig. $2 b)$. hsa-miR-135b-5p expression was - 16-fold reduced in 2D cultures transfected with antimiRs $(P=0.002$, Fig. 2 c) and -100 -fold reduced in 3D cultures $(P=0.003$, Fig. $2 \mathrm{~d})$. A statistical summary of the transfection results is presented in Additional file 1: Table S2.

In silico predictions indicated DNMT3A and CDC42 genes as targets of $h s a-m i R-29 c-5 p$ and $A P C$ as a target of $h s a-$ miR-135b-5p

TargetCompare and miRTarBase online tools provided lists with several target genes for both miRNAs, however only the 


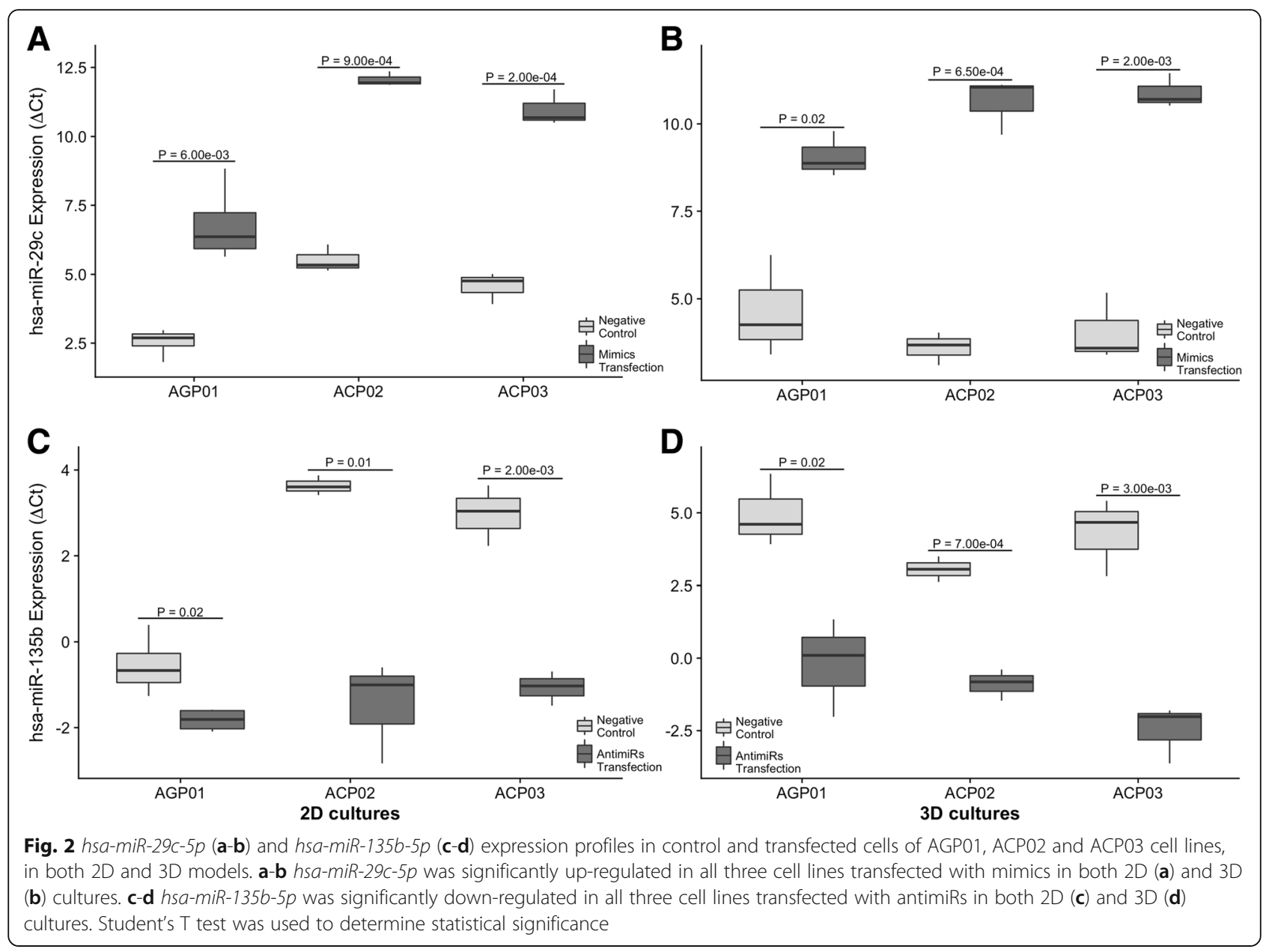

genes that were related to carcinogenesis, were predicted by both platforms and had a strong evidence of validation (Luciferase Reporter Assay, Western Blot and qPCR) according to miRTarBase were considered relevant to our study.

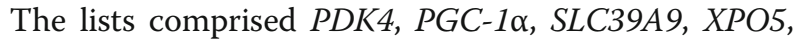
$D N M T 3 A$ and $C D C 42$ as possible target genes of hsa-miR-29c-5p and LPP, PPM1A and APC as possible target genes of $h s a-m i R-135 b-5 p$. When we compared these lists of possible target genes with the list of Driver genes of the carcinogenesis from Vogelstein et al. (2013), we observed that DNMT3A and $A P C$ were considered Driver genes and we chose to evaluate their expression after the transfection experiments. CDC42 was also chosen to be studied because it has a critical role in several metabolic pathways of cancer that leads to proliferation, migration and invasion (Qadir et al., 2015).

\section{$A P C, C D C 42$ and DNMT3A had their expressions altered after $h s a-m i R-135 b-5 p$ antimiRs and $h s a-m i R-29 c-5 p$ mimics transfection}

In order to verify if $A P C, C D C 42$ and $D N M T 3 A$ had their expressions regulated by $h s a-m i R-135 b-5 p$ and $h s a-m i R-29 c-5 p$, we quantified through western blot the expression of the proteins translated by those genes in control cells and in cells transfected with mimics of $h s a-m i R-29 c-5 p$ or antimiRs of $h s a-m i R-135 b-5 p$.

After the transfection with mimics of $h s a-m i R-29 c-5 p$, we observed a reduction in the expression of $C D C 42$ and DNMT3A in AGP01 and ACP03 2D cell lines and no changes between the control and the transfected cells of ACP02 2D cell line (Fig. 3a). In all three 2D cell lines transfected with antimiRs of $h s a-m i R-135 b-5 p$ we verified that the expression of $A P C$ was higher in the treated cells when compared to the control cells (Fig. $3 \mathrm{~b}$ ).

We, however, could not observe expression of any of the three proteins we studied in the $3 \mathrm{D}$ cultures of the three cell lines. The proteins did quantify in Bio-Rad protein reagent (Data not shown) but was not possible to obtain data from those cultures in the SDS-PAGE, so we are only showing data obtained from 2D cell cultures (Fig. 3).

\section{Discussion}

Highly sophisticated mechanisms of gene regulation act simultaneously in order to maintain homeostasis and the 


B
APC
B-Actin

good functioning of the cell. One of these mechanisms is the gene regulation by miRNAs, a class of small noncoding RNAs that physically repress the translation of their target mRNAs. miRNAs have a tissue-specific expression profile [24] and several studies found that characteristic expression profile to be altered in complex diseases such as cancer [15, 18, 19, 25-29].

Previous studies from our group found that the miRNAs $h s a-m i R-29 c-5 p$ and $h s a-m i R-135 b-5 p$ were down-regulated and up-regulated, respectively, in gastric cancer when compared to normal gastric mucosa $[7,17]$ and other studies as well have identified these miRNAs as differentially expressed in other types of cancer $[9,13,30,31]$. Our aim in this present study was to verify the expression profile of these two miRNAs in 2D and 3D cultures, modulate their expression profile and quantify the expression of its target genes after the transfection with mimics of hsa-miR-29c-5p and antimiRs of hsa-miR-135b-5p.

According to our previous studies, we expected to found a down expression of $h s a-m i R-29 c$ and an overexpression of hsa-miR-135b in cancer samples [7, 17]. In this present study we evaluated the expression profile of miRNAs $h s a-m i R-29 c-5 p$ and $h s a-m i R-135 b-5 p$ in gastric cancer cell lines, both in $2 \mathrm{D}$ and $3 \mathrm{D}$ by magnetic levitation models. We found that $h s a-m i R-29 c-5 p$ was down-regulated in the 3D culture of ACP02 and hsa-miR-135b-5p was up-regulated in the 3D culture of AGP01 (Fig. 1), implying that the three-dimensional conformation of those cell lines influenced those miRNAs expression profile.

$3 \mathrm{D}$ in vitro models have been widely used in biomedical research since they present characteristics that resembles an in vivo environment, such as the intercellular communication, hypoxia, resistance to drugs, angiogenesis signaling and a tumor microenvironment [32-37].

To further investigate the role of the miRNAs hsa$m i R-29 c-5 p$ and $h s a-m i R-135 b-5 p$ in $2 \mathrm{D}$ and 3D cultures of gastric cancer, we modulated the expression of both miRNAs in three different GC cell lines and measured the expression of the protein coded by their target genes DNMT3A, CDC42 (for hsa-miR-29c-5p) and APC (for $h s a-m i R-135 b-5 p)$. As shown in Fig. 2, all cell lines transfected with mimics had an up-regulation of hsa$m i R-29 c-5 p$ of at least 23 fold and cells transfected with antimiRs had a down-regulation of hsa-miR-135b-5p of at least - 2.3-fold. After the transfection experiments, we then proceeded to evaluate if the target genes of the two studied miRNAs suffered a major change in their expression as well.

Despite ACP02 and AGP01 3D cultures presented a differential expression of $h s a-m i R-29 c-5 p$ and $h s a-$ $m i R-135 b-5 p$, respectively, in relation to their $2 \mathrm{D}$ counterpart, we could not observe any protein expression in none of the three cell lines. Total protein lysates of 3D cultures did quantify in Bio-Rad protein reagent but did 
not separate by molecular weight in the SDS-PAGE, and this result can be explained since the three-dimensional conformation alters the protein composition, specially of extracellular matrix components [38]. This change in protein conformation and composition can be influencing in bonds between proteins making them stronger, leading to a non separation in SDS-PAGE.

In AGP01 and ACP03 2D cultures, cells transfected with mimics had an evident reduction in DNMT3A and CDC42 in relation to the control cells (Fig. 3). In ACP02 $2 \mathrm{D}$ cell line, we did not observe significant differences in the expression of both genes between transfected and control cells. This can be explained since ACP02 is a cell line originated from a diffuse gastric cancer and this GC subtype is known to have distinct risk factors from the intestinal subtype [39]. So, despite $h s a-m i R-29 c-5 p$ being differentially expressed in diffuse cancer, $D N M T 3 A$ and $C D C 42$ genes are not being regulated effectively by this miRNA and are being activated by another pathway.

The $A P C$ gene presented an up-regulated expression in the 2D cultures of all three transfected cell lines when compared to the control cells. This result corroborates the findings of Valeri et al. [12] in colorectal cancer and demonstrates that this gene is being actively regulated by $h s a-m i R-135 b-5 p$ in both intestinal and diffuse gastric cancer.

Up-regulation of $C D C 42$ and DNMT3A genes and down-regulation of $A P C$ gene in gastric cancer have several implications in the malignancy of the cell. $A P C$ is a tumor-suppressor gene and has an important role in the negative regulation of the Wnt signaling pathway, a key pathway that promotes cell proliferation and migration due $\beta$-catenin overexpression, which induces the transcription of oncogenes such as c-Myc $[40,41]$. APC regulates $\beta$-catenin by being a fundamental part of a multi-protein complex that marks it for proteasomal degradation [42]. Thus, down-regulation of $A P C$ caused by $h s a-m i R-135 b-5 p$ enhanced activity leads to a higher transduction signaling within the $\beta$-catenin/Wnt pathway, and consequently a higher proliferative capacity of malignant cells.

$A P C$ loss of function, especially due frameshift and nonsense mutations, or down-regulation is a major cause in the colorectal tumorigenesis and it's been proposed its loss is sufficient to induce carcinogenesis [42, 43]. Our results indicate that $A P C$ down-regulation is also an important risk factor to the development of gastric cancer and that this gene may have a crucial function in gastrointestinal malignant neoplasia.

Overexpression of CDC42 is responsible for the initiation of several biochemical cascades such as cell polarity, cytoskeleton remodeling and migration. Dysregulation in the expression of this gene grants oncogenic activities to the cell and it is associated to cancer development and metastasis [44]. CDC42 also negatively regulates the expression of p53 and knockdown of CDC42 via hsa-miR-29 family increased p53-dependent apoptosis in cervical carcinoma cells [45].

Up-regulation of CDC42 in gastric cancer was observed by Cheng et al. [46] and their study showed that hsa-miR-133 was down-regulated in GC samples and demonstrated that exogenous expression of this miRNA regulated the CDC42 levels in GC cell lines.

Since $h s a-m i R-29 c-5 p$ and $h s a-m i R-133$ are down-regulated in gastric cancer $[7,17,46]$ and have the same target gene $(C D C 42)$, it's possible to observe that independent mechanisms are altered in a similar way to maintain the malignant state of the cell. Our study showed that the exogenous expression of $h s a-m i R-29 c-5 p$ is also able to regulate the expression of $C D C 42$ in intestinal type gastric cancer cell lines, suggesting that this miRNA is another fundamental element in the regulation of this gene.

Up-regulation of DNMT3A was already correlated with the down-regulation of $h s a-m i R-29 c-5 p$ in cutaneous melanoma and in gastric cancer $[9,31]$. Ngyuen et al. [31] observed in cutaneous melanoma that the expression of $D N M T 3 A$ increased as the pathological staging of the disease progressed and the $h s a-m i R-29 c-5 p$ expression decreased according to the stage of the disease. These results suggest that dysregulation of both $h s a-m i R-29 c-5 p$ and DNMT3A occur in the beginning of the carcinogenesis and are important factors to the tumor progression.

Our study investigated the relation between the expression of $h s a-m i R-29 c-5 p$ and the expression of DNMT3A in three GC cell lines and our results showed that the expression of this miRNA and this gene are inversely correlated. Cui et al. [9] observed that the down-regulation of $h s a-m i R-29 c-5 p$ in gastric cancer is due the methylation of the promoter region of the MIR29C gene and up-regulation of DNMT3A caused higher rates of migration and invasion of malignant cells. The same authors also found that overexpression of DNMT3A is responsible for methylating the $\mathrm{CpG}$ islands in the $\mathrm{CDH} 1$ promoter region, which lead to E-cadherin down regulation and increased malignancy of gastric cancer cells. DNMT3A also down regulates $\mathrm{p} 18^{\mathrm{INK} 4 \mathrm{C}}$ (an important cell cycle regulator and inhibitor of CDK4/6-CyclinD complexes) in a methylation-dependent manner, which leads to increased cell proliferation in gastric cancer [47].

Understanding how the dynamics of gene regulation, via miRNA activity, function within distinct histological subtypes of gastric cancer is essential to elucidate new mechanisms that allow a certain gene or signaling pathway to remain expressed. We observed that $C D C 42$ and $D N M T 3 A$ remained expressed after the transfection of $h s a-m i R-29 c-5 p$ mimics in the diffuse subtype gastric cancer cell line, so investigating what molecular pathways are activated to allow these genes to be constitutively expressed may reveal a unique gene signature of 
such aggressive cancer and new targets for a more personalized therapeutic approach for patients with that disease.

In silico analysis utilizing miRTarBase (an experimentally validated microRNA-target interactions database - http:// mirtarbase.mbc.nctu.edu.tw/php/index.php) showed that both hsa-miR-135a and hsa-miR-135b shared APC as a target gene; we also saw that $h s a-m i R-29 a, h s a-m i R-29 b$ and hsa-miR-29c had CDC42 and DNMT3A as target genes. Since in previous works [7] we observed that in samples from our population both $h s a-m i R-29 c$ and $h s a-m i R-135 b$ were the most relevant and differentially expressed miRNAs, we selected those two specific miRNAs from their family members to be studied in the present work.

In vitro and in vivo modulation of miRNAs may represent a promising alternative in the search of new therapeutic targets since they act in critical pathways altered in cancer, specially those that promotes cell proliferation, migration and invasion. Utilizing 3D in vitro models allows a better representation of the spatial conformation observed in vivo, mainly because the composition of the extracellular matrix and a presence of a tumor microenvironment. Hageman et al. [48] showed that not only immortalized cancer cell lines but cells from a primary malignant tumor can undergo 3D spheroids, which allows a high throughput screening method for current or even new therapies to treat cancer in a more efficient and personalized manner.

Gastric cancer is an aggressive disease with poor rates of survival after diagnosis, and our results suggest molecular pathways that may contribute to such aggressiveness. Therefore, here we suggest an scheme of the possible signaling pathways activated by both $h s a-m i R-29 c$ and $h s a-$ miR-135b, through regulation of DNMT3A, CDC42 and $A P C$ genes. It is possible that the aberrant expression of these miRNAs in GC allows the activation of molecular mechanisms considered to be hallmarks of cancer such as invasion, migration, cell proliferation and inhibition of apoptosis (Fig. 4).

Therapies based in the modulation of miRNAs expression are promising and altering the expression of $h s a-$ $m i R-29 c-5 p$ and $h s a-m i R-135 b-5 p$, as well as a higher number of miRNAs can allow an alternative or neoadjuvant therapy to current treatments employed in the management of gastric cancer.

\section{Conclusions}

Cells cultured in a 3D environment showed differences in molecular and morphological aspects from the traditional monolayer method, meaning that this three-dimensional culture can be a more representative in vitro model that resembles better the in vivo reality.

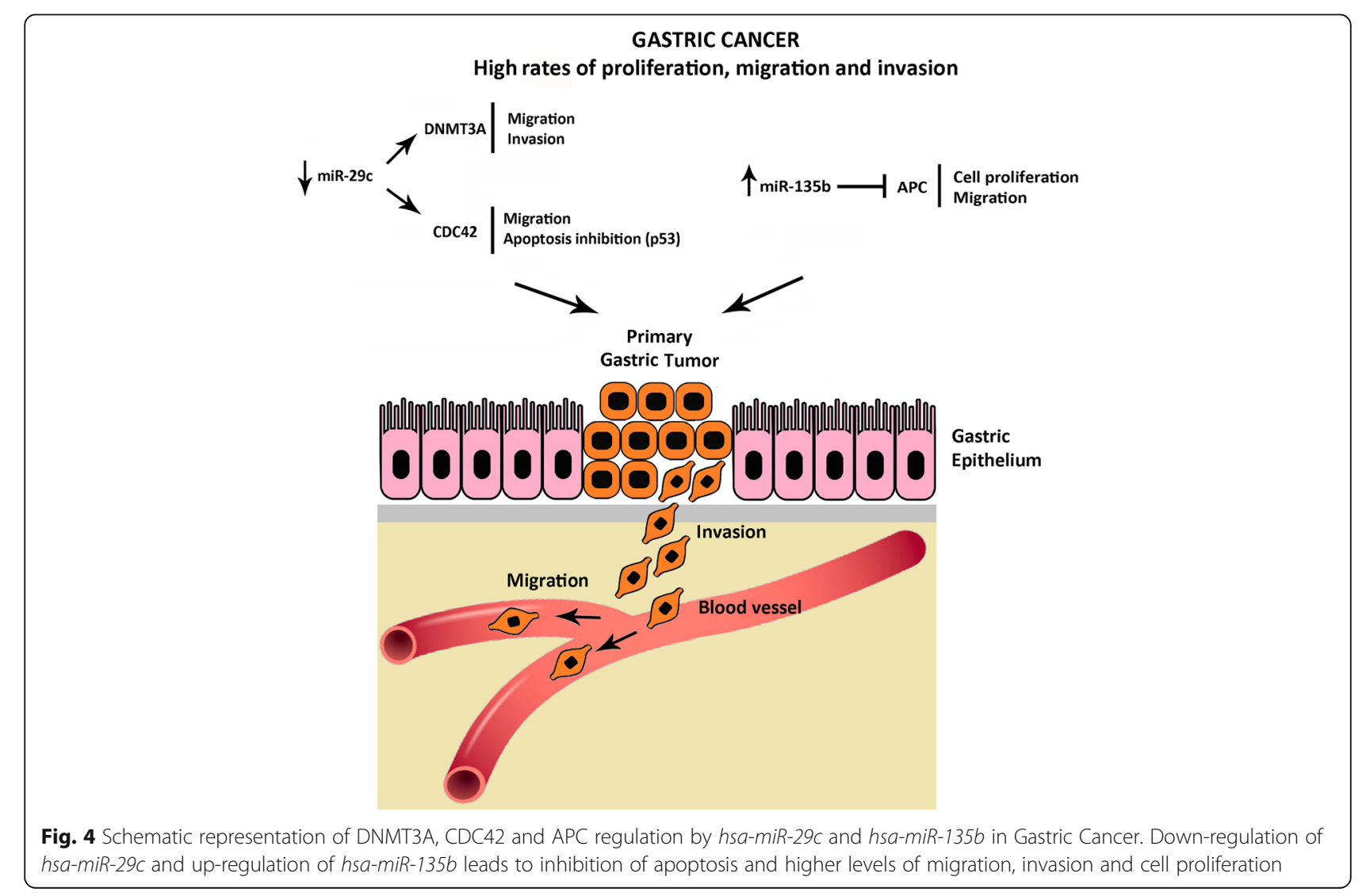


Modulating the expression of the investigated miRNAs caused their target genes to alter their expression in gastric cancer cell lines. DNMT3A and CDC42 genes had its expression down-regulated after the transfection of $h s a-m i R-29 c-5 p$ mimics in intestinal subtype cell lines and had no difference in its expression on diffuse subtype cell line, implying that these two genes are fundamental to the more aggressive characteristics of this cancer and are being activated by alternative pathways. $A P C$ had its expression up-regulated after the transfection of antimiRs of $h s a-m i R-135 b-5 p$ in all three GC cell lines, implying that this miRNA is a major regulator of this gene in gastric carcinogenesis.

Interfering in miRNAs expression profiles that act in key signaling pathways responsible for processes such as proliferation, invasion and apoptosis in vitro or in vivo models can reveal new and more personalized therapeutic targets for the management of gastric cancer.

\section{Additional file}

Additional file 1: Table S1. Statistical summary of the miRNAs hsa-miR29c-5p and hsa-miR-135b-5p expression profiles between 2D and 3D cell cultures. Table S2. Statistical summary of the transfection experiments of hsa-miR-29c-5p mimics and hsa-miR-135b-5p antimiRs in AGP01, ACP02 and ACP03 cell lines, both in 2D and in 3D models in relation to its negative control counterpart. (DOCX $20 \mathrm{~kb}$ )

\section{Abbreviations}

2D: Two-dimensional; 3D: Three-dimensional; GC: Gastric cancer; miRNAs: microRNAs

\section{Acknowledgments}

Not applicable.

\section{Funding}

This work is part of the Rede de Pesquisa em Genômica Populacional Humana (Biocomputacional-Protocol No. 3381/2013/CAPES) and of Antagomirs e Mimics como Ferramentas Biotecnológicas na Terapêutica do Câncer Gástrico (MCTI/CNPq/Universal 14/2014 - No. 457672/2014-5). Financial support: CAPES; PROPESP/UFPA-FADESP; MS/Decit, CNPq and FAPESPA. Ândrea Ribeiro-dos-Santos is supported by CNPq/Produtividade (304413/2015-1). The authors confirm that the funder had no influence over the study design, content of the article, or selection of this journal.

\section{Availability of data and materials}

Not applicable.

\section{Authors' contributions}

$L M, L G Q, D C F L, A F V, A L P$ and $L C D P$ performed the experiments. $L M$ realized the statistical analysis. LM and ALP prepared the Figs. LM, JJVP, LRG, PPA and ARS conceived the study. LM and ARS drafted the manuscript. LM, AFV, JJVP, LRG, PPA, ASK, RB and ARS revised critically the manuscript. All authors reviewed and approved the final manuscript.

\section{Ethics approval and consent to participate}

The study was reviewed and approved by the Ethics Committee of the University Hospital João de Barros Barreto from the Federal University of Pará (protocol number: 132/08), in accordance with the Helsinki Declaration of 1964.

\section{Consent for publication}

Not applicable.

\section{Competing interests}

The authors declare that they have no competing interests.

\section{Publisher's Note}

Springer Nature remains neutral with regard to jurisdictional claims in published maps and institutional affiliations.

\section{Author details}

'Laboratório de Genética Humana e Médica, Instituto de Ciências Biológicas, Universidade Federal do Pará, Belém, Brazil. ${ }^{2}$ Núcleo de Pesquisas em Oncologia, Hospital Universitário João de Barros Barreto, Universidade Federal do Pará, Belém, Brazil. ${ }^{3}$ Laboratório de Neuropatologia Experimental, Hospital Universitário João de Barros Barreto, Universidade Federal do Pará, Belém, Brazil. ${ }^{4}$ Laboratório de Cultivo Celular, Faculdade de Odontologia, Instituto de Ciências da Saúde, Universidade Federal do Pará, Belém, Brazil. ${ }^{5}$ Laboratório de Nanobiotecnologia, Instituto de Genética e Bioquímica, Universidade Federal de Uberlândia, Uberlândia, Brazil. ${ }^{\circ}$ Laboratório de Citogenética Humana, Instituto de Ciências Biológicas, Universidade Federal do Pará, Belém, Brazil.

Received: 8 March 2018 Accepted: 21 October 2018

Published online: 30 October 2018

\section{References}

1. Jemal A, Bray F, Center MM, Ferlay J, Ward E, Forman D. Global cancer statistics. CA Cancer J Clin. 2011;61:69-90.

2. Torre LA, Bray F, Siegel RL, Ferlay J, Lortet-Tieulent J, Jemal A. Global cancer statistics, 2012. CA Cancer J Clin. 2015;65:87-108.

3. McLean MH, El-Omar EM. Genetics of gastric cancer. Nat Rev Gastroenterol Hepatol. 2014;11:664-74.

4. Chatzinikolaidou M. Cell spheroids: the new frontiers in in vitro models for cancer drug validation. Drug Discov Today. 2016;21:1553-60.

5. Pampaloni F, Reynaud EG, Stelzer EH. The third dimension bridges the gap between cell culture and live tissue. Nat Rev Mol Cell Biol. 2007;8:839-45.

6. Bartel DP. MicroRNAs: genomics, biogenesis, mechanism. and function Cell. 2004:116:281-97.

7. Darnet S, Moreira FC, Hamoy IG, Burbano R, Khayat A, Cruz A, et al. Highthroughput sequencing of miRNAs reveals a tissue signature in gastric Cancer and suggests novel potential biomarkers. Bioinform Biol Insights. 2015;9:1-8.

8. Tseng C-WW, Lin C-CC, Chen C-NN, Huang H-CC, Juan H-FF. Integrative network analysis reveals active microRNAs and their functions in gastric cancer. BMC Syst Biol. 2011;5:99.

9. Cui H, Wang L, Gong P, Zhao C, Zhang S, Zhang K, et al. Deregulation between miR-29b/c and DNMT3A is associated with epigenetic silencing of the $\mathrm{CDH} 1$ gene, affecting cell migration and invasion in gastric cancer. PLoS One. 2015;10:e0123926.

10. He Y, Wang J, Wang J, Yung WY, Hsu E, Li A, et al. MicroRNA-135b regulates apoptosis and chemoresistance in colorectal cancer by targeting large tumor suppressor kinase 2. Am J Cancer Res. 2015;5:1382-95.

11. Imam JS, Plyler JR, Bansal H, Prajapati S, Bansal S, Rebeles J, et al. Genomic loss of tumor suppressor miRNA-204 promotes cancer cell migration and invasion by activating AKT/mTOR/Rac1 signaling and actin reorganization. PLoS One. 2012;7:e52397.

12. Valeri N, Braconi C, Gasparini P, Murgia C, Lampis A, Paulus-Hock V, et al. MicroRNA-135b promotes cancer progression by acting as a downstream effector of oncogenic pathways in colon cancer. Cancer Cell. 2014;25:469-83.

13. Li Y, Xu D, Bao C, Zhang Y, Chen D, Zhao F, et al. MicroRNA-135b, a HSF1 target, promotes tumor invasion and metastasis by regulating RECK and EVI5 in hepatocellular carcinoma. Oncotarget. 2015;6:2421-33.

14. Lu Y, Hu J, Sun W, Li S, Deng S, Li M. MiR-29c inhibits cell growth, invasion, and migration of pancreatic cancer by targeting ITGB1. Onco Targets Ther. 2016;9:99-109.

15. Wang $H$, Zhu $Y$, Zhao $M$, Wu C, Zhang $P$, Tang $L$, et al. miRNA-29C suppresses lung cancer cell adhesion to extracellular matrix and metastasis by targeting integrin $\beta 1$ and matrix metalloproteinase2 (MMP2). PLoS One. 2013;8:e70192.

16. Ribeiro-dos-Santos Â, Khayat ASS, Silva A, Alencar DO, Lobato J, Luz L, et al. Ultra-deep sequencing reveals the microRNA expression pattern of the human stomach. PLoS One. 2010;5:e13205. 
17. Vidal AF, Cruz AM, Magalhães L, Pereira AL, Anaissi AK, Alves NCC, et al. HsamiR-29c-5p and hsa-miR-135b-5p differential expression as potential biomarker of gastric carcinogenesis. World J Gastroenterol. 2016;22:2060-70.

18. Arigoni M, Barutello G, Riccardo F, Ercole E, Cantarella D, Orso F, et al. miR$135 \mathrm{~b}$ coordinates progression of ErbB2-driven mammary carcinomas through suppression of MID1 and MTCH2. Am J Pathol. 2013;182:2058-70.

19. Matsuo M, Nakada C, Tsukamoto Y, Noguchi T, Uchida T, Hijiya N, et al. MiR$29 \mathrm{c}$ is downregulated in gastric carcinomas and regulates cell proliferation by targeting RCC2. Mol Cancer. 2013;12:15.

20. Zhao X, Li J, Huang S, Wan X, Luo H, Wu D. MiRNA-29c regulates cell growth and invasion by targeting CDK6 in bladder cancer. Am J Transl Res. 2015;7:1382-9.

21. Leal MF, Nascimento JL, Silva CE, Lamarão MF, Calcagno DQ, Khayat AS, et al. Establishment and conventional cytogenetic characterization of three gastric cancer cell lines. Cancer Genet Cytogenet. 2009;195:85-91.

22. Schmittgen TD, Livak KJ. Analyzing real-time PCR data by the comparative C(T) method. Nat Protoc. 2008;3:1101-8

23. Munhoz CD, Lepsch LB, Kawamoto EM, Malta MBB, Lima L de S, Avellar MC, et al. Chronic unpredictable stress exacerbates lipopolysaccharide-induced activation of nuclear factor-kappaB in the frontal cortex and hippocampus via glucocorticoid secretion. J Neurosci. 2006;26:3813-20.

24. Ludwig N, Leidinger $P$, Becker $K$, Backes C, Fehlmann T, Pallasch C, et al. Distribution of miRNA expression across human tissues. Nucleic Acids Res. 2016:44:3865-77.

25. Ding D-PP, Chen Z-LL, Zhao X-HH, Wang J-WW, Sun J, Wang Z, et al. miR29c induces cell cycle arrest in esophageal squamous cell carcinoma by modulating cyclin E expression. Carcinogenesis. 2011;32:1025-32.

26. Jung HS, Seo Y-RR, Yang YM, Koo JH, An J, Lee SJ, et al. Ga12gep oncogene inhibits FOXO1 in hepatocellular carcinoma as a consequence of miR-135b and miR-194 dysregulation. Cell Signal. 2014;26:1456-65.

27. Pass HI, Goparaju C, Ivanov S, Donington J, Carbone M, Hoshen M, et al. Hsa-miR-29c-5p* is linked to the prognosis of malignant pleural mesothelioma. Cancer Res. 2010;70:1916-24.

28. Wang Z, Zhang H, He L, Dong W, Li J, Shan Z, et al. Association between the expression of four upregulated miRNAs and extrathyroidal invasion in papillary thyroid carcinoma. Onco Targets Ther. 2013;6:281-7.

29. Xu S, Cecilia Santini G, De VK, Vande Broek I, Leleu X, De BA, et al. Upregulation of miR-135b is involved in the impaired osteogenic differentiation of mesenchymal stem cells derived from multiple myeloma patients. PLoS One. 2013:8:e79752.

30. Pei H, Jin Z, Chen S, Sun X, Yu J, Guo W. MiR-135b promotes proliferation and invasion of osteosarcoma cells via targeting FOXO1. Mol Cell Biochem. 2015;400:245-52

31. Nguyen T, Kuo C, Nicholl MB, Sim M-SS, Turner RR, Morton DL, et al. Downregulation of microRNA-29c is associated with hypermethylation of tumor-related genes and disease outcome in cutaneous melanoma. Epigenetics. 2011;6:388-94.

32. Baker BM, Chen CS. Deconstructing the third dimension: how 3D culture microenvironments alter cellular cues. J Cell Sci. 2012;125:3015-24.

33. Fischbach C, Kong HJ, Hsiong SX, Evangelista MB, Yuen W, Mooney DJ. Cancer cell angiogenic capability is regulated by 3D culture and integrin engagement. Proc Natl Acad Sci U S A. 2009;106:399-404.

34. Minchinton Al, Tannock IF. Drug penetration in solid tumours. Nat Rev Cancer. 2006;6:583-92.

35. Wartenberg M, Budde $P$, De MM, Grünheck F, Tsang SY, Huang Y, et al. Inhibition of tumor-induced angiogenesis and matrix-metalloproteinase expression in confrontation cultures of embryoid bodies and tumor spheroids by plant ingredients used in traditional chinese medicine. Lab Investig. 2003;83:87-98.

36. Stevanato $L$, Sinden JD. The effects of microRNAs on human neural stem cell differentiation in two- and three-dimensional cultures. Stem Cell Res Ther. 2014;5:49.

37. Tseng H, Gage JA, Shen T, Haisler WL, Neeley SK, Shiao S, et al. A spheroid toxicity assay using magnetic 3D bioprinting and real-time mobile devicebased imaging. Sci Rep. 2015;5:13987.

38. Longati P, Jia X, Eimer J, Wagman A, Witt M-RR, Rehnmark S, et al. 3D pancreatic carcinoma spheroids induce a matrix-rich, chemoresistant phenotype offering a better model for drug testing. BMC Cancer. 2013;13:95.

39. Marqués-Lespier JM, González-Pons M, Cruz-Correa M. Current perspectives on gastric Cancer. Gastroenterol Clin N Am. 2016:45:413-28.
40. Nagel R, le SC, Diosdado B, van der WM, Oude Vrielink JA, Bolijn A, et al. Regulation of the adenomatous polyposis coli gene by the miR-135 family in colorectal cancer. Cancer Res. 2008;68:5795-802.

41. Munemistu S, Albert I, Souza B, Rubinfeld B, Polakis P. Regulation of intracellular beta-catenin levels by the adenomatous polyposis coli (APC) tumor-suppressor protein. Proc Natl Acad Sci U S A. 1995;92(7):3046-50.

42. Ayala-Calvillo E, Mojica-Vázquez L, García-Carrancá A, González-Maya L. Wnt/ $\beta$-catenin pathway activation and silencing of the APC gene in HPV-positive human cervical cancer-derived cells. Mol Med Rep. 2018;17(1):200-8.

43. Liu S, Tackmann NR, Yang J, Zhang Y. Disruption of the RP-MDM2-p53 pathway accelerates APC loss-induced colorectal tumorigenesis. Oncogene. 2016:36:1374-83.

44. Stengel K, Zheng Y. Cdc42 in oncogenic transformation, invasion, and tumorigenesis. Cell Signal. 2011;23:1415-23.

45. Park SY, Lee J, Ha M, Nam JW, Kim VN. miR-29 miRNAs activate p53 by targeting p85a and CDC42. Nat Struct Mol Biol. 2009;16(1):23-9.

46. Cheng Z, Liu F, Wang G, Li Y, Zhang H, Li F. miR-133 is a key negative regulator of CDC42-AK pathway in gastric cancer. Cell Signal sciencedirect. 2014;26:2667-73.

47. Cui H, Zhao C, Gong P, Wang L, Wu H, et al. DNA methyltransferase $3 A$ promotes cell proliferation by silencing CDK inhibitor p18 $8^{\text {INK4C }}$ in gastric carcinogenesis. Sci Rep. 2015:5:13781.

48. Hageman J, Jacobi C, Hahn M, Schmid V, Welz C, Schwenk-Zieger S, et al. Spheroid-based 3D cell cultures enable personalized therapy testing and drug discovery in head and neck Cancer. Anticancer Res. 2017;37:2201-10.

\section{Ready to submit your research? Choose BMC and benefit from:}

- fast, convenient online submission

- thorough peer review by experienced researchers in your field

- rapid publication on acceptance

- support for research data, including large and complex data types

- gold Open Access which fosters wider collaboration and increased citations

- maximum visibility for your research: over 100M website views per year

At BMC, research is always in progress.

Learn more biomedcentral.com/submissions 